\title{
Determination of amount of land subsidence based on INSAR and LiDAR monitoring for a dike strengthening project
}

\author{
Michel de Koning ${ }^{1}$, Jacco K. Haasnoot ${ }^{1}$, Rob R. van Buuren ${ }^{1}$, Marco Weijland ${ }^{2}$, and Cor Bisschop ${ }^{3}$ \\ ${ }^{1}$ CRUX Engineering BV, Amsterdam, 1086XK, the Netherlands \\ ${ }^{2}$ Hoogheemraadschap van Schieland en de Krimpenerwaard, Rotterdam, 3063GK, the Netherlands \\ ${ }^{3}$ Greenrivers BV, Amersfoort, 3811EJ, the Netherlands \\ Correspondence: Michel de Koning (dekoning@cruxbv.nl)
}

Published: 22 April 2020

\begin{abstract}
For the dike strengthening project Krachtige IJsseldijken Krimpenerwaard (KIJK) a study has been undertaken to optimize the amount of land subsidence. Based on archive information originally a subsidence rate of $11 \mathrm{~mm} \mathrm{yr}^{-1}$ is used in the design calculations. This means that for a 50-year period an additional $0.55 \mathrm{~m}$ must be considered which does not comply with the macro-stability problems of the dike. Based on INSAR and LiDAR measurement data and reanalysing the archive data, the rate of subsidence is determined at an average of $8 \mathrm{~mm} \mathrm{yr}^{-1}$. This could mean a reduction of $27 \%$ on the amount of soil needed to balance subsidence.
\end{abstract}

\section{Introduction}

Since January 2017 the assessment of safety for primary dikes in the Netherlands should comply to the WBI2017, see MIM (2017). One of the criteria to be checked is the height of the dike to withstand hydraulic loading conditions. The level of the dike crest is an important factor, so the amount of land subsidence must be considered. This paper covers the determination of land subsidence for the dike strengthening project Krachtige IJsseldijken Krimpenerwaard (KIJK). The $10 \mathrm{~km}$ long KIJK project is located next to the river Hollandse IJssel, in the Krimpenerwaard near Rotterdam, the Netherlands, see Fig. 1. The Krimpenerwaard is an area consisting of soft Holocene soil layers with ongoing subsidence mainly caused by changing groundwater levels and the associated drying out and oxidation of peat. The rate of subsidence for the crest of the dike itself is different from that of the hinterland. Based on information of the Water authority "Hoogheemraadschap van Schieland en de Krimpenerwaard" (HHSK) the average rate of subsidence for the crest of the dike is about $11 \mathrm{~mm} \mathrm{yr}^{-1}$. For the project this means that for the period 2025-2075, besides effects of sea level rise an additional $0.55 \mathrm{~m}$ of subsidence must be considered. Large parts of the dike also do not comply for macro stability which means that every additional load on top of the dike would increase the stability problem. A study has been undertaken to determine the rate of subsidence based on monitoring data from INSAR and LiDAR measurements (IB-KIJK, 2017). This paper covers the result from the performed study.

\section{Method of analysis}

The first step was to plot all the data of each dataset to determine an average subsidence rate along the dike. Also, the "outliers" in the data could visually been recognized and

the locations of these outliers can be determined. Explanations for these outliers were sought based on different factors such as, the soil profile, the profile of the Hollandse IJssel underneath the waterline or other activities, e.g. previous strengthening projects on parts of the dike or road works. Based on the explanation of the outliers the assumption was made that a subsidence rate of more than $20 \mathrm{~mm} \mathrm{yr}^{-1}$ is caused by external circumstances and is therefore excluded from the data. Also, measurements that indicated a rise in a measurement period were not considered. After filtering the data for each dataset, a weighted average of the subsidence rate is determined. With this weighted average an overall av- 


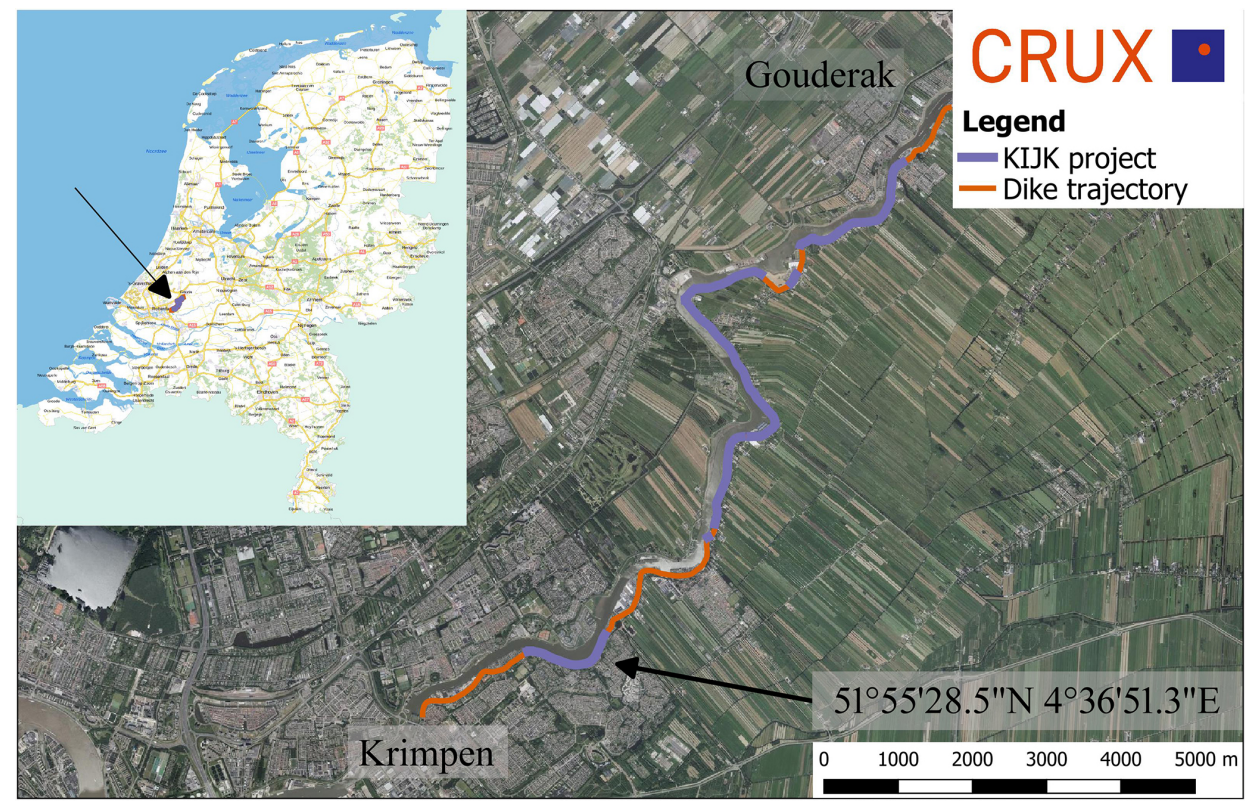

Figure 1. Location KIJK project; Hollandse IJssel between Krimpen - Gouderak [aerial photo 2016; nationaal georegister].

erage subsidence rate for the entire dike is determined as well as more specific average subsidence rate for each dike section.

\section{Analysis of archive data}

The first step of the study was to reanalyse the archive data of HHSK on which an average subsidence rate of $11 \mathrm{~mm} \mathrm{yr}^{-1}$ for crest of the whole dike trajectory was determined. The data consisted from the measured settlements of the dike at different moments in the period 1961-2007. In Fig. 2 all the data from the dataset of HHSK is shown. In the graph also data of the period 2007-2011 is shown. It was found that the average subsidence of $11 \mathrm{~mm} \mathrm{yr}^{-1}$ was determined only with the data from this short period. With the analysis it was also found that the data for 2011 was based on extrapolation from data during the period 1961-2007. In the determination of a new subsidence rate the data from the period 2007-2011 is disregarded. In the data from HHSK, an increased rate of subsidence in the period 2003-2007 can be seen, which causes the weighted average of the subsidence rate to increase considerably. Also, in the period 1971-1981 a higher rate of subsidence is noted. From the weighted average it appears that a bandwidth for the subsidence rate is found between 5 and $10 \mathrm{~mm} \mathrm{yr}^{-1}$ with a few outliers towards the $15 \mathrm{~mm} \mathrm{yr}^{-1}$. The average rate of subsidence over the entire dike is approximately $7 \mathrm{~mm} \mathrm{yr}^{-1}$.

\section{Monitoring Data from INSAR and LiDAR measurements}

To determine the rate of subsidence for the crest of the dike, monitoring data from INSAR and LiDAR measurement is analysed.

\subsection{INSAR (Interferometric Synthetic Aperture Radar)}

INSAR is a technique that determines deformations of surface points based on radar satellite measurements. With this technique the deformation from a point can be measured with high precision, in the order of millimetres. It must be noted that the precision depends on the weather conditions during the time of measurement and the resolution of the satellite. For the INSAR measurements, data from points located on the crest of the dike during the period between 2013 and 2016 is used. The used satellite data is generated and processed by SkyGeo and is shown in Fig. 3. From the weighted average it appears that a reasonably good bandwidth between 5 and $10 \mathrm{~mm} \mathrm{yr}^{-1}$ can be obtained with a few outliers towards the $20 \mathrm{~mm} \mathrm{yr}^{-1}$. The average rate of subsidence over the entire dike is approximately $7 \mathrm{~mm} \mathrm{yr}^{-1}$.

\subsection{LiDAR (Light Detection and Ranging of Laser Imaging Detection And Ranging)}

Also, the Current Dutch Elevation (Actueel Hoogtebestand Nederland, AHN) is used for determining the subsidence rate. The AHN map is a digital height map for the Netherlands based on 3D-height information obtained by LiDAR measurement from airplanes or helicopters. The map con- 


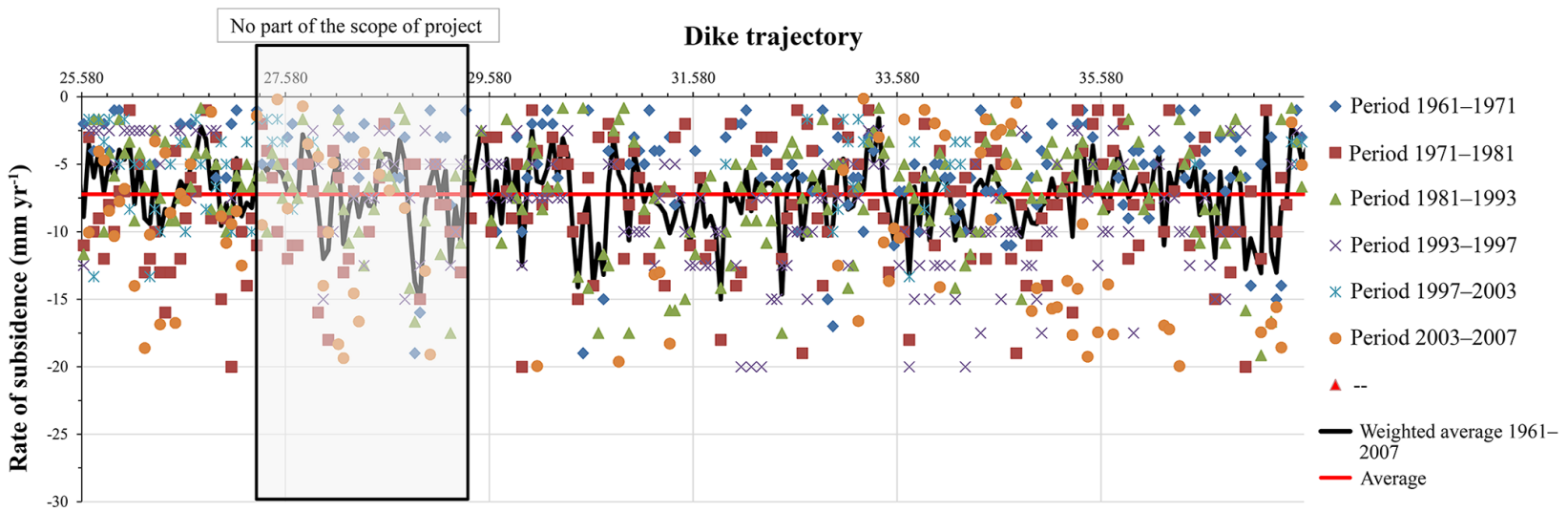

Figure 2. Determination of average subsidence rate based on HHSK archive data.

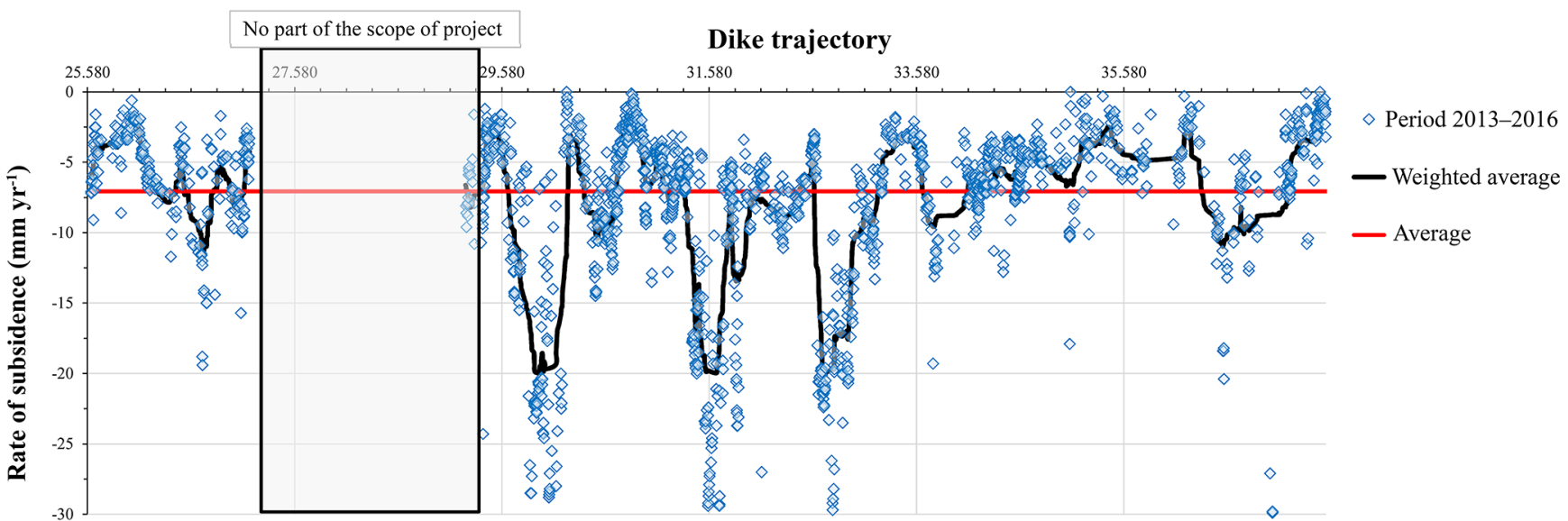

Figure 3. Determination of average subsidence rate based on INSAR measurements from the period 2013-2016.

tains detailed and precise information based on an average of eight measurements per square meter. AHN has a systematic error of $5 \mathrm{~cm}$ and stochastic error of $5 \mathrm{~cm}$ (https: //data.overheid.nl, Open data van de Overheid, 2019). In general, it can be stated that only a good indication of the subsidence can be found if it is greater than the scatter in the measurements, $15 \mathrm{~cm}$. It is of course possible that a better estimate can be made by combining various data files, so that a more reliable statement can be made than just based on AHN (http://www.ahn.nl, Ahn, 2019). For determining the subsidence from AHN the data from version 2 (2008) is compared with version 3 (2014). To do this the difference in the AHN data was determined with the aid of QGis. The resulting rate of subsidence between these periods is shown in Fig. 4. From the difference between AHN2 and AHN3 it appears that a bandwidth between $5 \mathrm{~mm} \mathrm{yr}^{-1}$ and $15 \mathrm{~mm} \mathrm{yr}^{-1}$ is obtained with a few outliers towards the $20 \mathrm{~mm} \mathrm{yr}^{-1}$. In the AHN data, two outliers in the subsidence rate stand out.

These peaks are in the ranges $\mathrm{Hm} 29.75-30.1$ and $\mathrm{Hm}$ 32.65-33.05. These outliers are in good agreement with 2 of the 3 outliers as found in the measurement data of the INSAR measurements. The average subsidence rate from the LiDAR data over the entire dike is approximately $9 \mathrm{~mm} \mathrm{yr}^{-1}$.

\section{Comparison Data from different methods}

The comparison of weighted average of the subsidence rate from the three different datasets is shown in Fig. 5. From the graph it can be concluded that:

1. Between 25.58 and 27.1 a good agreement is found between all the datasets. It is noticed that in the $\mathrm{Li}^{-}$ DAR data outliers are found above $10 \mathrm{~mm} \mathrm{yr}^{-1}$ and even $1 \mathrm{~mm} \mathrm{yr}^{-1}$ which are not found in the HHSK and INSAR data.

2. In the INSAR and LiDAR for the trajectory $29.75-30.2$ and 32.65-33.0 peaks are found in the subsidence rate. These peaks are not present in the HHSK data. This could be explained that by the fact that the INSAR and LiDAR measurements (respectively 2013-2016 and 2008-2014) are of a later period than the data from HHSK (1961-2007). 


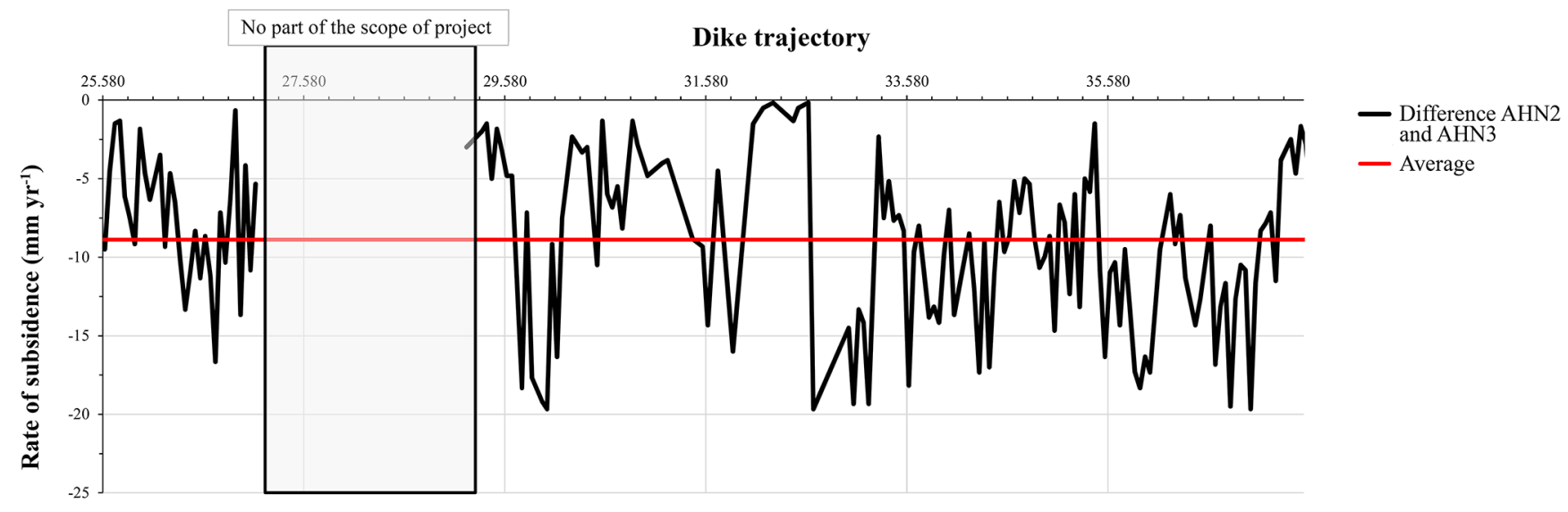

Figure 4. Determination of average subsidence rate based on difference in LiDAR data from 2008 and 2014.

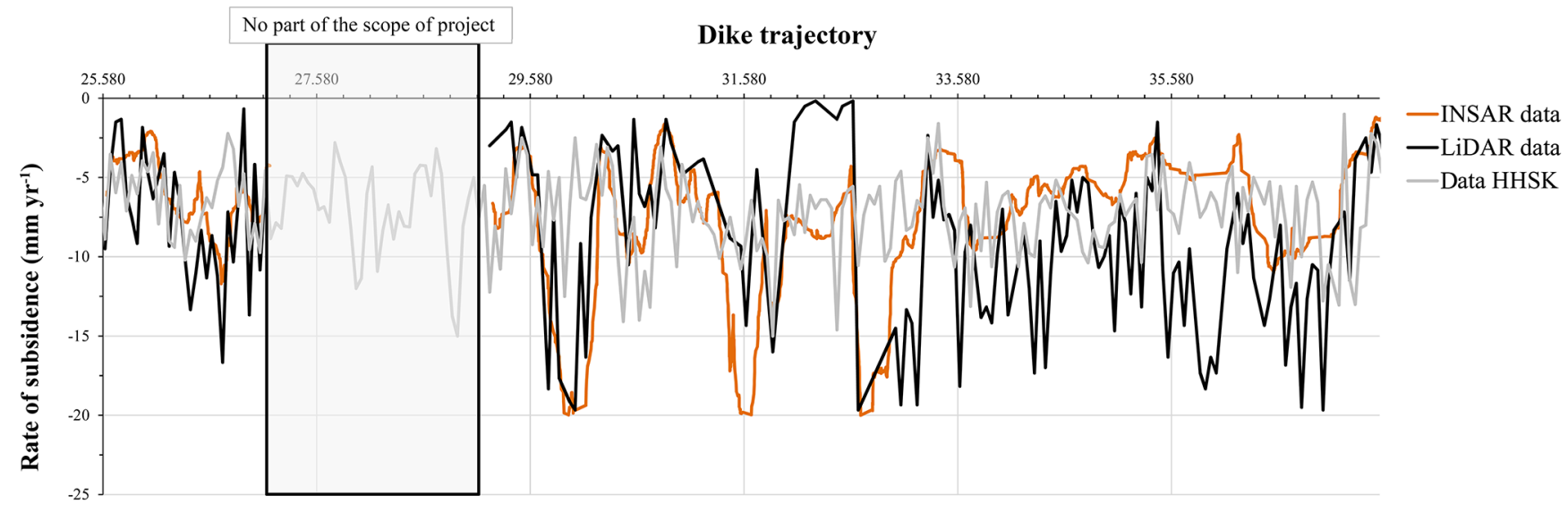

Figure 5. Comparison of subsidence rate determined with different measurement methods and HHSK archive data.

3. Between the trajectory 30.2 and 32.65 the determined subsidence rate for the three datasets well matches. Excluding the outlier in the INSAR between approximately 31.4 and 31.7 and an outlier with a very low subsidence rate in the LiDAR between approximately 32.05 and 32.65 .

4. For the trajectory 33.0 to 37.53 the subsidence rate as found from the INSAR data and from HHSK reasonably match. The data from the LiDAR data shows generally a higher subsidence rate.

5. In general, the INSAR data and the HHSK data give almost the same average subsidence rate for the entire dike of about $7 \mathrm{~mm} \mathrm{yr}^{-1}$. The average subsidence rate based on the LiDAR data is $8.9 \mathrm{~mm} \mathrm{yr}^{-1}$.

In Fig. 6 the determined subsidence rate for the whole trajectory as well for a specific dike section is shown. For the dike sections $\mathrm{N}$ until $\mathrm{U}$ the LiDAR data shows a higher subsidence rata of about $4 \mathrm{~mm} \mathrm{yr}^{-1}$. Since the INSAR and LiDAR data are taken in almost the same period and based on specification of HHSK that there was no strengthening project in this period or road works it is concluded that the difference can be explained by the difference in accuracy of the methods, INSAR measurement is more accurate than LiDAR measurement. Also, the different methods don't consist of the same measurements point. Explanations were sought for the peaks in the determined subsidence. This was done by relating the subsidence to the thickness of the settlement sensitive soft Holocene layers (organic clay and peat layers) underneath the crest of the dike or previous work to the dike. In Fig. 7 the comparison of the subsidence rate and the thickness of the Holocene soil layers along the dike trajectory is given. Based on this graph no clear conclusion can be drawn of a relation between a higher subsidence and the thickness of the soft Holocene layers.

Also, a relation was sought between the subsidence rate and the profile of the Hollandse IJssel underneath the waterline as determined with bathymetry (IB-KIJK, 2017). For some locations the bathymetry showed a steeper underwater slope or a local deepening of the bottom. This can indicate a weaker location in the dike with a trigger for outward movement of the dike, which can cause a higher subsidence rate. 


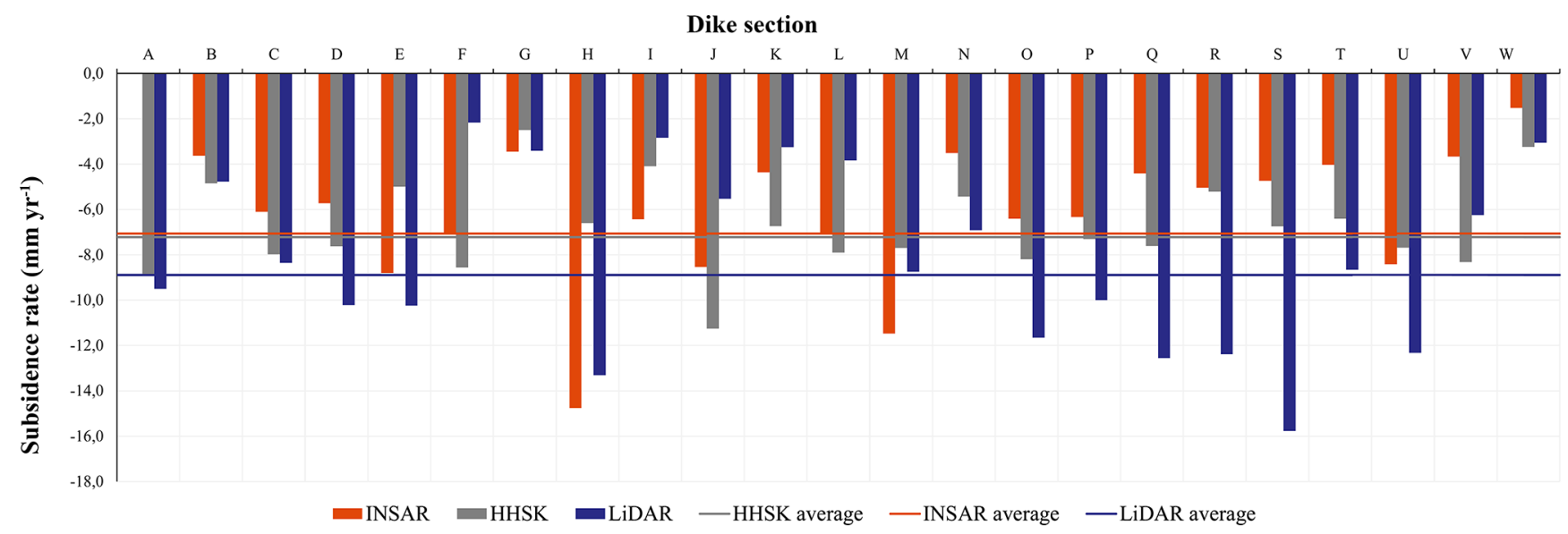

Figure 6. Comparison of subsidence rate for every dike section as determined with the three different datasets.

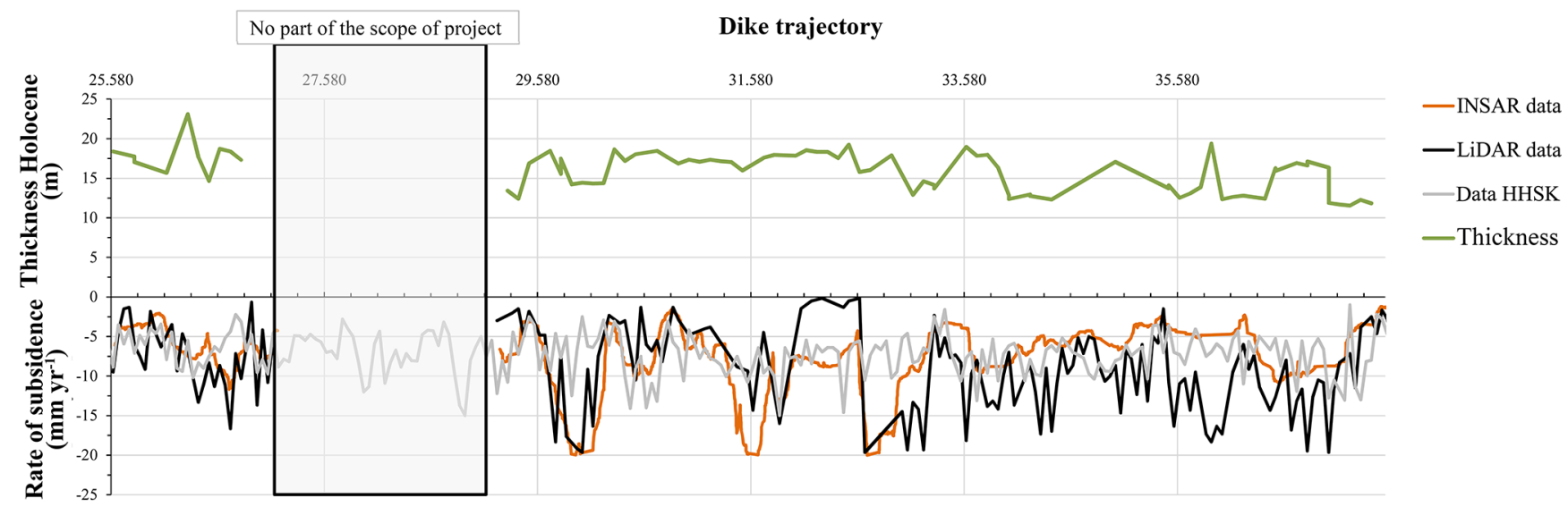

Figure 7. Comparison of determined subsidence rate with thickness Holocene soil layers.

For some locations along the dike this relation was found, but overall there was not a good explanation of a higher subsidence rate due to the underwater profile of the Hollandse IJssel.

\section{Conclusions}

In this paper the INSAR and LiDAR monitoring data and the determination of the rate of the subsidence for the KIJK dike project are discussed. Based on the results from this study the rate of subsidence for the crest of the dike could be reduced from an average of $11 \mathrm{~mm} \mathrm{yr}^{-1}$ to an average of $8 \mathrm{~mm} \mathrm{yr}^{-1}$. This could mean a reduction of $27 \%$ on the amount of soil needed to counteract for the subsidence. The used analysis provides HHSK a method for future projects to get a better estimate of the rate of subsidence of dikes, which helps to design dike-strengthening more economically.
Data availability. A request for the provision of the data, as owned by HHSK, will be treated by HHSK based on the purpose of the request. To determine whether the request can be granted, the purpose must be specified.

Author contributions. MK and RRB made the analysis of the data. JKH, CB gave advice during the analysis. MW was representative of the HHSK for the project. MK prepared the manuscript with contribution from all co-authors.

Competing interests. The authors declare that they have no conflict of interest.

Special issue statement. This article is part of the special issue "TISOLS: the Tenth International Symposium On Land Subsidence - living with subsidence". It is a result of the Tenth International Symposium on Land Subsidence, Delft, the Netherlands, 17-21 May 2021 
Acknowledgements. The work presented in this paper is part of the KIJK dike strengthening project in the Netherlands. The authors would like to thank their partners from IB-KIJK, BWZ Ingenieurs and Infram and the anonymous reviewers for their comments to improve the quality of the paper.

\section{References}

AHN: available at: https://www.ahn.nl, last access: 14 June 2019.

IB KIJK: memo Autonome Bodemdaling dijk, 17 August 2017 (in Dutch).

Ministerie van Infrastructuur en Milieu (MIM): Schematiseringshandleiding macrostabiliteit, WBI2017, version 2.1, 2017 (in Dutch).

Open data van de Overheid: available at: https://data.overheid. nl/dataverzoeken/vliegdata-ahn2-en-ahn3, last access: 16 June 2019 (in Dutch). 